\title{
Recursos Educacionais Abertos para o Ensino de Física: um curso de extensão para licenciandos brasileiros e colombianos ${ }^{+*}$
}

Douglas Grando de Souza ${ }^{1}$

Mestrando em Ensino de Física - Universidade Federal do Rio Grande do Sul Elkin Adolfo Vera Rey ${ }^{1}$

Doutorando em Ensino de Física - Universidade Federal do Rio Grande do Sul Ives Solano Araujo ${ }^{1}$

Eliane Angela Veit ${ }^{1}$

Instituto de Física - Universidade Federal do Rio Grande do Sul

Porto Alegre - RS

\section{Resumo}

Este artigo tem como objetivo apresentar um relato da experiência de planejamento e desenvolvimento do curso de extensão Recursos Educacionais Abertos para o Ensino de Física. O curso, na modalidade a distância, foi planejado tendo como base a Teoria Social da Aprendizagem de Etienne Wenger. Seu objetivo foi congregar licenciandos de Física colombianos e brasileiros, buscando favorecer o eventual surgimento de uma Comunidade de Prática interessada no desenvolvimento de Práticas Educacionais Abertas no Ensino de Física. Realizado ao longo de doze semanas, com carga horária de 30h, o curso contou com a participação inicial de 40 licenciandos de Física. Destacam-se, nas atividades do curso, a busca e ensaio de solução de situações-problema da sala de aula de professores de Física, através do trabalho colaborativo em equipes. Todas as atividades conjuntas foram realizadas em ambientes de comunicação e de trabalho colaborativo virtuais e open source. Após o fim do curso, alguns dos participantes demonstraram interesse na continuidade das ideias e atividades - desenvolvendo um trabalho conjunto até a presente data.

\footnotetext{
${ }^{+}$Open Educational Resources for Physics Education: an extension course for Brazilian and Colombian undergraduates

* Recebido: maio de 2019.

Aceito: agosto de 2019.

${ }^{1}$ E-mails: douglas.grando@ufrgs.br; licfisielk82@gmail.com; ives@if.ufrgs.br; eav@if.ufrgs.br
} 
Palavras-chave: Recursos Educacionais Abertos; Práticas Educacionais Abertas; Comunidade de Prática; Formação de Professores; Ensino de Física.

\begin{abstract}
This paper aims to present an experience report of the design and implementation of a distance learning course focused on Open Educational Resources (OER) and based on Etienne Wenger's Social Theory of Learning. The main goal was to bring together Brazilian and Colombian undergraduates to start a future Community of Practice around the use of OER in physics education. The course was carried out in 30 hours over the period of twelve weeks with the enrollment of 40 pre-service physics teachers. As main activities, we can highlight the collaborative work involved in the search for classroom problem-situations, faced by physics teachers at high school, that can be tackled using OER, as well the elaboration of the respective plans solve it. All joint activities were carried out in virtual and open source digital platforms. After the end of the course, some of the participants demonstrated interest in to keep in touch and have been working together to date.
\end{abstract}

Keywords: Open Educational Resources; Open Educational Practices; Community of Practice; Teachers' Education; Physics Education.

\title{
I. Introdução
}

A quase totalidade dos ambientes sociais está permeada e é continuamente transformada pelas Tecnologias Digitais da Informação e Comunicação (TDIC), demonstrando sua importância na sociedade atual. Assim, também no contexto das iniciativas para reformas educativas se destaca o importante papel atribuído a essas tecnologias. Segundo a Organização das Nações Unidas para a Educação, a Ciência e a Cultura, as TDIC “devem ser aproveitadas para fortalecer os sistemas de educação, a disseminação do conhecimento, o acesso à informação, a aprendizagem de qualidade" (UNESCO, 2016, p. 8). No contexto iberoamericano, o documento Metas Educativas 2021: A educação que queremos para a geração dos bicentenários, que apresenta os principais desafios a serem superados para melhorar a qualidade e equidade da educação ibero-americana e fazer frente à pobreza e desigualdade social da região, define uma intenção de efetiva inserção e incorporação das TDIC nos contextos de ensino e aprendizagem (OEI, 2010, p. 115). Em atenção à realidade dos países ibéricos e latino-americanos definem-se duas linhas de ação necessárias para integração das TDIC no contexto escolar: a manutenção da infraestrutura tecnológica e a elaboração de delinea- 
mentos pedagógicos para sua utilização, inserida em um projeto pedagógico curricular, acrescentando a necessidade de contar com professores qualificados em processos de inovação pedagógica com o uso de tecnologias (ibid., p. 115-116).

Ao professor é atribuído papel de protagonista de muitas das esperadas transformações educativas; dentre elas, a geração de espaços que proporcionem a acesso ao conhecimento de maneira significativa, com a introdução das TDIC em sua prática educacional em sala de aula (MARTINEZ; LEITE; MONTEIRO, 2015). Como consequência, a formação inicial de professores passa a contar com a necessidade do desenvolvimento de competências profissionais associadas à aprendizagem de TDIC e a sua integração às práticas educativas em sala de aula. Entretanto, a literatura indica que são lentos os passos dados para a introdução efetiva de elementos de uso e reflexão acerca das TDIC na formação inicial de professores. Alguns fatores evidenciam a baixa incorporação das tecnologias digitais da informação e comunicação às práticas docentes dos professores em formação, tais como: o baixo número e/ou localização tardia de disciplinas nas grades curriculares dos cursos de licenciatura (LOPES; FÜRKOTTER, 2016; ANDRADE; COELHO, 2018); as dificuldades logísticas associadas à utilização das TDIC ou descrença em sua utilização efetiva no ensino público (MARCOLLA, 2008); o modelo formativo docente marcado por uma perspectiva instrumental-técnica que não contempla nem reflexão sobre a prática nem a prática refletida, como a enfatizada por Medeiros e Medeiros (2002) e Dantas et al. (2014). Assim, conforme evidenciado por Schuhmacher, Alves Filho e Schuhmacher (2017), as TDIC se tornam muitas vezes uma carga a mais no currículo da formação inicial de professores, uma imposição técnica, impedindo uma verdadeira inovação no fazer docente.

Dentre as práticas que, de maneira emergente, têm contribuído para a atribuição de um novo papel às TDIC na educação estão as chamadas Práticas Educacionais Abertas (PEA). Sendo cunhadas no projeto The Open Educational Quality Initiative (OPAL) em 2010, as PEA podem ser compreendidas como um conjunto de atividades e ações que se caracterizam pela ênfase nos processos de criação e compartilhamento de conhecimentos através do desenvolvimento, uso e modificação de Recursos Educacionais Abertos (REA), abrindo assim novas possibilidades para a criação e difusão de conhecimento (SANTOS, 2012; ARIMOTO; BARROCA; BARBOSA, 2014). Santos (2013, p. 21-23), ao realizar um resgate histórico das ideias associadas ao termo Recurso Educacional Aberto, permite defini-los de maneira sucinta como materiais de ensino, aprendizagem e pesquisa que se distinguem devido ao licenciamento aberto a que são submetidos. Dentre os recursos que podem ser considerados como REA, se devidamente licenciados, estão: softwares, textos, simulações computacionais, livros didáticos, dados de pesquisas científicas, maquetes, textos de apoio ao aluno e professor, lições e notas de aula, apresentações multimídia, imagens e vídeos, artigos científicos, etc. Apesar disso, para o propósito deste trabalho, nos limitamos aos REA encontrados em formato digital. 
A licença aberta, ou copyleft, assegura para aqueles que utilizam REA quatro liberdades fundamentais (UNESCO, 2012): liberdade de acesso, em formato que permita a qualquer usuário o acesso aos conteúdos de um recurso educacional aberto; liberdade de uso, que garanta a plena utilização do material em qualquer dispositivo digital; liberdade de adaptação, através de formatos passíveis de edição, permitindo a estudo, compreensão, cópia de parte do seu conteúdo e aprimoramento da estrutura do recurso; e liberdade de redistribuição, que possibilite o compartilhamento do recurso e de suas informações, de modo pago ou não. Ao mesmo tempo, as licenças abertas asseguram aos autores a manutenção de seu direito autoral de propriedade intelectual, sendo sempre necessária a especificação da autoria para a plena utilização das liberdades fundamentais (UNESCO, 2015, p. 2). Desse modo, é possível compreender o potencial desses recursos para a educação em perspectivas de acesso, criação e compartilhamento de conhecimentos.

Mesmo com o papel atribuído às TDIC nas práticas educativas proporcionadas pelo uso de REA, os desafios formativos dos professores persistem. Como, então, pode-se ressignificar o papel das TDIC na formação inicial de professores, não se tornando um peso formativo em meio a tantos outros atribuídos ao professor? Além dos muros e paredes da escola e da universidade, cresce o número de iniciativas de colaboração e difusão de conhecimentos utilizando as tecnologias. Um exemplo dessas iniciativas é a Wikipedia, a enciclopédia livre, um projeto de enciclopédia colaborativa e universal, com conhecimento de licenciamento livre ${ }^{2}$. Destaca-se o voluntariado dos participantes e a capacidade de utilização dos recursos tecnológicos necessários à consecução desse projeto.

Espaços não formais de educação tendem a dar conta de necessidades educativas humanas que surgem naturalmente e que, somente em um momento posterior, se tornam necessidades institucionalizadas (GOHN, 2016). Essa integração das TDIC em espaços não formais de aprendizagem é, na nossa visão, uma oportunidade para dar respostas às nossas inquietações quanto ao papel desses recursos na formação inicial de professores, proporcionando um modelo de formação alternativo àquele tradicionalmente desenvolvido nas instituições de Ensino Superior.

Nos espaços de educação não formal, a aprendizagem dos sujeitos é relacionada com sua socialização, isto é, acontece nas diversas configurações sociais em que se encontram, sendo impregnadas de valores, cultura e pertencimento (ibid.). Consideramos que um modelo adequado para estabelecer a relação entre a integração de TDIC na formação de professores e a aprendizagem em ambientes não formais seja a Teoria da Aprendizagem Social. Essa teoria tem como fundamento o conceito de Comunidades de Prática (CoP), termo cunhado no início da década de 1990 pelo pesquisador independente Etienne Wenger e pela antropóloga Jean Lave, e aprofundado por Wenger ao longo de sua carreira. As CoP se referem a estruturas sociais emergentes em que a aprendizagem é compreendida através da participação social em

\footnotetext{
2 Para maiores informações acerca do projeto, acesse <https://en.wikipedia.org/wiki/Wikipedia:About>. Acesso em: abr. 2019.
} 
práticas realizadas conjuntamente e da transformação das identidades dos membros da comunidade (WENGER, 2001, p. 22).

Como cultivar uma Comunidade de Prática de professores de Física em formação inicial? ${ }^{3}$ Que empreendimento comum poderia ser valoroso para essa comunidade? Considerou-se que um domínio atraente para uma CoP de professores de Física poderia ser Práticas Educacionais Abertas no Ensino de Física, enfocando a utilização e produção de Recursos Educacionais Abertos. Como um primeiro passo para congregar licenciandos com interesse nesses assuntos decidiu-se ofertar um curso de extensão planejado de acordo com o referencial wengeriano. Eventualmente alguns desses participantes poderiam vir a constituir, no futuro, uma $\mathrm{CoP}$ em torno dos tópicos discutidos no curso. Contudo, vale a pena destacar que não se supõe que a atividade de extensão em si, de caráter formal, seja uma Comunidade de Prática. O que supomos é que a experiência e o convívio social oportunizados pelo curso poderiam servir para a emergência posterior de uma CoP.

Nesse artigo, relatamos o planejamento e desenvolvimento desse curso de extensão oferecido pela Universidade Federal do Rio Grande do Sul (UFRGS), a professores de Física em formação inicial de quatro Instituições de Ensino Superior, duas brasileiras e duas colombianas. O curso teve como título-tema Recursos Educacionais Abertos no Ensino de Física.

Na próxima seção descrevemos estudos anteriores que versam sobre CoP associadas à formação de professores; na seção III, os elementos centrais da Teoria Social de Aprendizagem de Wenger; na seção IV, o planejamento didático do curso, fundamentado nos princípios de Wenger para o cultivo de comunidades de prática e na seção V relatamos a experiência didática. Seguem-se os comentários finais.

\section{Comunidades de Prática na Formação de Professores}

O referencial teórico de Comunidades de Prática tem sido utilizado como ferramenta para um modelo alternativo de formação inicial e continuada de professores, baseado na aprendizagem decorrente da participação social. Akerson et al. (2012) analisam a forma como cinco professores em formação inicial abordam questões relacionadas à Natureza da Ciência $(\mathrm{NdC})$ em suas aulas ao serem apoiados pela participação em uma Comunidade de Prática de pesquisadores e licenciandos. As autoras relatam o crescimento na elaboração de adequadas visões de $\mathrm{NdC}$ demonstradas pelos participantes da CoP, o desenvolvimento de uma preocupação de realizar um ensino de ciências coerente com essas visões e de diferentes formas de ensino de $\mathrm{NdC}$ pelos diferentes participantes. O papel da CoP se mostrou de fundamental importância para o desenvolvimento dos licenciandos, contribuindo para sua formação através da criação e manutenção de relações de compromisso e ajuda mútua, do estabelecimento de

\footnotetext{
${ }^{3}$ Esta é uma das questões de pesquisa do doutorado do segundo autor deste trabalho, junto ao Programa de PósGraduação em Ensino de Física da Universidade Federal do Rio Grande do Sul.
} 
um objetivo claro e persistente de desejar a introdução dos conhecimentos de $\mathrm{NdC}$ em sala de aula e o compartilhamento de ideias, recursos didáticos e interpretações.

Os estudos de García, Greca e Meneses (2008) e El-Hani e Greca (2013) sobre formação continuada de professores, reconhecendo a insuficiência de cursos isolados para suprir as necessidades concretas da sala de aula, trazem luz a essa questão através das experiências de aprendizagem social em Comunidades de Prática virtuais. Para os autores, a melhora na formação de professores - em especial na formação continuada - está diretamente relacionada com a melhora na qualidade da educação. Paradoxalmente, avaliam que poucos professores efetivamente modificam suas práticas docentes, em parte por conta da diferença entre a formação vivenciada e a realidade escolar, em parte por não disporem de um contexto social de apoio que facilite e valorize as mudanças a serem realizadas. Também indicam que as $\mathrm{CoP}$ podem ser utilizadas como uma ferramenta para o desenvolvimento de uma formação continuada de professores situada no próprio ambiente de trabalho desses profissionais. García, Greca e Meneses (2008) relatam a experiência piloto de uma comunidade de aprendizagem virtual de professores do ensino fundamental, alunos e especialistas em ensino de ciências de universidades brasileiras e espanholas, entre os anos de 2003 e 2004. El-Hani e Greca (2013) se debruçam sobre o que denominaram ComPrática, uma comunidade virtual, formada por professores de Biologia e pesquisadores do Ensino de Biologia e implementada em 2007 em parceria com uma universidade federal brasileira - avaliando as interações dos componentes ao longo dos dois primeiros anos da comunidade. Os autores conseguem identificar traços de Comunidades de Prática na história e desenvolvimento das duas comunidades. O relato da experiência piloto evidenciou as diferentes percepções acerca dos projetos desenvolvidos por parte de professores e especialistas, o domínio de novas ferramentas conceituais e metodológicas ocorrido por meio da participação social, e a existência de dificuldades de comunicação, em especial entre professores e pesquisadores. Por outro lado, o estudo sobre o ComPrática permitiu aos autores perceber diferentes níveis de participação, o desenvolvimento de um conjunto de recursos compartilhados pelos membros da comunidade e o reconhecimento no outro de alguém capaz de prestar auxílio às dificuldades enfrentadas.

Outros trabalhos destacam aspectos interessantes sobre o uso de Comunidades de Prática na formação de professores. Clarke (2009) apresenta a possibilidade de um curso de formação continuada de professores de Geografia ser desenvolvido com base na perspectiva de CoP. Esse estudo se diferencia do nosso trabalho porque i) tem como base outra área de conhecimento e nível de formação dos professores, e ii) parte-se do princípio que a CoP ganharia vida e serviria ao curso de formação, ao invés do curso servir como base promotora de uma tentativa de estabelecimento futuro de uma Comunidade de Prática. Gretton, Bridges e Fraser (2017), por sua vez, desenvolvem um estudo acerca da formação da identidade de professores-assistentes de Física, ao reconhecer que a formação de uma identidade profissional em um contexto social é fundamental para a modificação das práticas docentes. Realizam um estudo de caso apoiando-se no referencial wengeriano situando a transformação da identidade 
em Comunidades de Prática de professores-assistentes. Os autores relatam as modificações na identidade de um professor-assistente, através de sua participação social em conjunto com outros professores-assistentes, culminando em práticas docentes mais esclarecidas e embasadas em pesquisas na área de ensino de ciências.

\section{Comunidades de Prática}

O conceito de Comunidade de Prática foi aprofundado por Wenger (2001) durante sua construção de uma Teoria Social da Aprendizagem. Nessa perspectiva, a aprendizagem é compreendida enquanto participação social, situando-se na inter-relação de quatro dimensões (WENGER, 2001, p. 22): (1) o significado, que caracteriza a capacidade humana de experimentar o viver no mundo como algo significativo; (2) a prática, que corresponde aos recursos históricos e sociais compartilhados nas $\mathrm{CoP}$; (3) a comunidade, representando a configuração social, o grupo de pessoas com um compromisso entre si e suas interações; e (4) a identidade, enquanto dimensão pessoal e social, compreendendo as mudanças provocadas pela aprendizagem nos indivíduos. À luz dessas quatro dimensões, a aprendizagem é entendida como experiência de negociação de significados, de filiação e pertencimento, de competências valorizadas e de identificação ocorridas em histórias de participação nas estruturas sociais chamadas Comunidade de Prática.

Ao buscarem definir uma estrutura para as CoP, Wenger, McDermott e Snyder (2002, p. 4, tradução nossa) as definem como "grupos de pessoas que partilham uma preocupação, um conjunto de problemas, ou uma paixão sobre uma temática, e que aprofundam seu conhecimento e especialidade nessa interagindo de maneira contínua". São assumidas como estruturas sociais, com toda a sua vivacidade e espontaneidade, que se distinguem pela capacidade de assumir a responsabilidade de promover a aprendizagem e desenvolver competências, bem como de criar e conservar conhecimentos (ibid., p. 11).

E, embora os autores reconheçam que uma Comunidade de Prática possa assumir diferentes formas, tamanhos, tempos de duração, nomes e estilos (ibid., p. 24), evidenciam-se na definição três elementos que caracterizam uma Comunidade de Prática e que, por isso, auxiliam na sua identificação e descrição: o domínio, a comunidade e a prática. Ao mesmo tempo, é possível perceber que esses três elementos são interdependentes, implicando-se entre si. O termo domínio se refere àquilo que interessa à comunidade, o campo de conhecimento ao qual se dedica. É, por isso, capaz de criar um terreno comum de identificação entre os membros da comunidade através da afirmação de valores e propósitos. Por meio do conhecimento do domínio da comunidade e de seus limites, os membros podem "decidir exatamente o que é valioso partilhar, como apresentar suas ideias e a quais atividades se dedicar" e também "reconhecer potencial em tentativas e ideias não finalizadas" (ibid., p. 28). A comunidade consiste naqueles que formam o "tecido social da aprendizagem" (ibid., p. 28). É formada por pessoas que possuem um compromisso mútuo voluntário que permeia suas inter-relações. Por fim, a prática se refere "ao conhecimento específico que uma comunidade desenvolve, 
partilha e mantém" (ibid., p. 29), sendo tácito e explícito, dinâmico e constantemente negociado entre os membros da comunidade.

Esses dois últimos elementos se relacionam intimamente em uma Comunidade de Prática. Wenger (2001, p. 99) salienta que a prática e a comunidade formam uma unidade, em que a prática assume o papel de elemento de coesão da Comunidade de Prática. Ao mesmo tempo, a prática não se encontra em manuais, livros detalhados, estruturas ou objetos, ainda que possa deles precisar, mas não existe em um abstrato, mas pertence a uma comunidade e reside na intensa participação dos seus membros (ibid. p. 100). Assim, o autor descreve três fatores que caracterizam a prática como fonte de coerência da comunidade: o compromisso mútuo, o empreendimento compartilhado e o repertório compartilhado.

O compromisso mútuo caracteriza a responsabilidade assumida perante os demais integrantes da comunidade, a relação de participação mútua por meio da qual os integrantes da comunidade realizam a prática. Falar em compromisso mútuo, para Wenger, não implica assumir que as relações sejam harmoniosas ou simples, pois ao mesmo tempo em que são mútuas, refletem toda a complexidade de realizar algo em conjunto. Nelas se encontram tanto convergências quanto divergências, diversidade e especialização em relação às capacidades pessoais de cada membro. Por essa razão, o compromisso mútuo é "intrinsecamente parcial" (WENGER, 2001, p. 103) e implica tanto aquilo que se sabe e se realiza para a comunidade quanto aquilo que não se sabe e não se pode realizar, com o qual o outro pode contribuir. A negociação de um empreendimento conjunto se associa ao elemento chamado de domínio do conhecimento e reflete a contínua interação entre os membros no sentido de definir aquilo que move a comunidade. É conjunto no sentido em que é negociado coletivamente (ibid., p. 106), não implicando que todos os membros possuam as mesmas ideias acerca de tudo. Ao mesmo tempo, não implica algo simplesmente assumido ou dado, sendo continuamente negociado entre seus membros ao longo do processo mesmo de desenvolvimento do empreendimento conjunto. O repertório compartilhado, por sua vez, caracteriza todos os recursos necessários para que uma comunidade possa desenvolver sua prática em compromisso mútuo, visando a consecução do empreendimento conjunto. Inclui tudo aquilo que a comunidade compartilha, como conceitos, símbolos, configurações espaciais, expressões faciais, histórias, atitudes, termos, ações, instrumentos, rotinas, discursos pelos quais os membros demonstram sua afiliação, etc. São simultaneamente históricos e ambíguos, pois possuem um contexto que lhes confere significado claro e, ao mesmo tempo, são maleáveis e podem ser reutilizados em diferentes contextos. Para que as práticas das CoP se estabeleçam e desenvolvam, é preciso permitir que esses três fatores de coerência sejam expressos na comunidade.

Apesar de serem caracterizadas por sua naturalidade, vivacidade, organicidade, espontaneidade e autodirecionamento, Wenger, McDermott e Snyder (2002, p. 50-51) deixam clara a possibilidade de cultivar Comunidades de Práticas. O cultivo não ocorre através de um planejamento restrito, de um seguimento de uma série de passos de uma receita, mas através da gestão de condições que favoreçam o surgimento e desenvolvimento daquilo que se culti- 
va. Assim, o planejamento de uma CoP se caracteriza como a promoção de um tecido social em que se possam estabelecer um compromisso mútuo entre as pessoas, negociar interesses e objetivos, construir e utilizar ferramentas que facilitem o desenvolvimento de uma prática comum. Para isso, Wenger, McDermott e Snyder (2002) definem sete princípios que devem orientar e fazer parte do projeto de uma comunidade como um todo:

1. Projetar para a Evolução. Um projeto de comunidade deve orientar e catalisar o desenvolvimento natural da Comunidade de Prática. Significa, em especial, estar aberto ao surgimento de novidades, de contribuições de novos membros e de mudanças de interesses - em si, um projeto dinâmico, em constante reajuste e negociação, que não termina com o surgimento da comunidade.

2. Abrir a um diálogo de perspectivas internas e externas à comunidade. O projeto de desenvolvimento de uma Comunidade de Prática é efetivo se há diálogo e participação de seus membros no seu desenvolvimento. Desse modo, as comunidades manterão sua capacidade de reconhecer seus próprios dilemas e interesses, ao mesmo tempo em que não se fecharão ao mundo exterior. São capazes de acolher aquilo que é externo na medida em que possa ser trazido para um diálogo com as informações internadas da CoP.

3. Convidar a diferentes níveis de participação. Aprender envolve uma história departicipação nas Comunidades de Prática - o que pode implicar variações no nível de participação ao longoda trajetória de vida na comunidade, conforme os interesses individuais se modificam. Um projeto adequado é capaz de identificar membros que se encontram no núcleo da Comunidade de Prática, ao mesmo tempo em que valoriza a participação ativa menos intensa e a participação periférica de outros membros.

4. Desenvolver espaços públicos e privados. Uma comunidade é rica em interrelacionamentos. Estão presentes tanto em ambientes públicos em seu dia a dia e programações em seu calendário - como encontros, reuniões, eventos - quanto em ambientes privados no seu dia a dia - relações mais próximas, cotidianas, entre os membros da comunidade. Um projeto deve, portanto, reservar espaço para o que se faz tanto com o todo, quanto no particular.

5. Enfoque nos valores. Uma comunidade prospera por que seus membros atribuem valor àquilo que fazem, aos outros, ao que os outros fazem e a suas relações. $\mathrm{O}$ valor é uma questão de grande importância para as comunidades, pois a afiliação dos seus membros é sempre voluntária. O projeto de uma Comunidade de Prática, portanto, deve incentivar os membros a explicitarem suas percepções acerca do valor da comunidade e daquilo que nela realizam. 
6. Combinar familiaridade e entusiasmo. Ao projetar uma comunidade de prática, é preciso levar em conta o equilíbrio que deve proporcionar aos seus membros. Essadeve ser um local reconhecível, familiar para seus membros, onde seus saberes sejam valorizados. Ao mesmo tempo, a Comunidade de Prática deve proporcionar agitação, vivacidade, a experiência do encontro com o novo.

7. Desenvolver um ritmo para a comunidade. Proporcionar a oportunidade de criação de ritmos de interação é indispensável, pois esse indicará para os membros o modo como serão realizados os trabalhos no interior da comunidade. O surgimento de um ritmo é, por isso, um dos maiores indicativos da vivacidade das Comunidades de Prática.

No relato apresentado nesse artigo, esses sete princípios foram utilizados para o planejamento de um curso de extensão que pudesse servir à promoção de uma comunidade de prática de licenciandos de Física e pesquisadores. O domínio de interesse dessa comunidade seria relacionado à criação e compartilhamento de Recursos Educacionais Abertos, bem como a atitude de reflexão sobre o uso desses recursos no Ensino de Física.

\section{Planejamento Didático}

Foi planejado, ao longo do segundo semestre de 2017 e do primeiro semestre de 2018, um curso de extensão a distância, com o objetivo de servir de base para o desenvolvimento de uma Comunidade de Prática virtual de professores de Física em formação inicial e pesquisadores da área de Ensino de Física. Chamado "Recursos Educacionais Abertos para o Ensino de Física", teve como tema o uso de REA nas práticas de professores de Física. Visou proporcionar a licenciandos de Física um ambiente em que pudessem aprender em conjunto sobre recursos e práticas pertinentes e úteis para sua formação enquanto professores de Física.

O curso aconteceu através da parceria entre a UFRGS e três Instituições de Ensino Superior, duas colombianas (Universidad Distrital Francisco José de Caldas, Bogotá, e Universidad de Antioquia, Medellin) e uma brasileira (IF-Sul/Visconde da Garça). Contou com uma equipe coordenadora composta por dois professores ministrantes, três professores colaboradores e dois tutores, vinculados às diferentes Instituições de Ensino Superior envolvidas no projeto, responsáveis pela idealização e consecução de todo o curso relatado. O público alvo escolhido foi licenciandos de Física dos últimos semestres do curso matriculados em uma dessas instituições. Essa escolha se deu com base na vivência dos licenciandos em uma intersecção entre escola e universidade, pois já envolvidos em estágios docentes, e no fato que, muito em breve, se encontrariam eles próprios como professores em sala de aula. Além disso, considerou-se que, ainda que o curso de extensão tivesse um público restrito, a comunidade que eventualmente emergiria deveria agregar novos membros, e seria mais promissora 
caso não se limitasse às fronteiras de um único país. Optou-se, então, pelos dois países de origem dos pesquisadores envolvidos.

O curso de extensão foi planejado com duração de 30 horas e composto por três lições, nas quais se problematizaram conhecimentos acerca de REA e TDIC no Ensino de Física. Essas lições se constituíram em textos elaborados pela equipe de coordenação, contendo os conhecimentos que o curso visaria trabalhar e situações-problema que seriam o foco dos trabalhos dos participantes do curso. Nas duas primeiras, foi apresentada uma situaçãoproblema idealizada, mas que de algum modo refletisse os contextos de sala de aula encontrados pelos professores de Física. Na última lição, porém, solicitou-se que os participantes trouxessem situações-problema de suas experiências cotidianas, sendo escolhidas duas delas para que se investissem esforços para um ensaio de solução.

Para que o curso ocorresse, elaborou-se uma estrutura inicial de dez encontros semanais síncronos, programados para que todos os participantes estivessem presentes simultaneamente. Além disso, foi necessário, ao longo do desenvolvimento do curso de extensão, adicionar um encontro extra para que os licenciandos pudessem ter mais tempo de trabalho em conjunto. O cronograma do Quadro 1 é o resultado do processo de planejamento do curso, ajustado de acordo com as dificuldades encontradas durante o decorrer do curso de extensão.

Quadro 1: Cronograma do curso de extensão.

\begin{tabular}{cl}
\hline Data & Atividade \\
\hline $\begin{array}{c}\text { 20/03 à } \\
11 / 04 / 2018\end{array}$ & Período de Inscrições. \\
\hline $27 / 04 / 2018$ & $\begin{array}{l}\text { Encontro 1 (síncrono) -Apresentação do curso. Interação inicial, motiva- } \\
\text { ções sobre estarem no curso. Explicar a dinâmica de interação. }\end{array}$ \\
\hline $04 / 05 / 2018$ & $\begin{array}{l}\text { Encontro 2 (síncrono) - Lição 1: Recursos Digitais e Objetos De Aprendi- } \\
\text { zagem: Busca e Uso Adequado. }\end{array}$ \\
\hline $11 / 05 / 2018$ & Encontro 3 (síncrono) - Atividade 1 e dúvidas. \\
\hline $18 / 05 / 2018$ & Encontro 4 (síncrono) - Lição 2: Recursos Educacionais Abertos. \\
\hline $25 / 05 / 2018$ & Encontro 5 (síncrono) - Atividade 2 e dúvidas. \\
\hline $01 / 06 / 2018$ & $\begin{array}{l}\text { Encontro 6 (síncrono) - Lição 3: Estratégias de Uso de REA e Práticas } \\
\text { Educacionais Abertas (PEA). }\end{array}$ \\
\hline $08 / 06 / 2018$ & Encontro 7 (síncrono) - Atividade 3 e dúvidas. \\
\hline $15 / 06 / 2018$ & Encontro 8 (síncrono) - Síntese das propostas de situação-problema. \\
\hline $22 / 06 / 2018$ & Encontro 9 (síncrono) - Escolha da situação-problema pelos grupos. \\
\hline $29 / 06 / 2018$ & Encontro 10- Trabalho em ensaios de solução. \\
\hline $13 / 07 / 2018$ & Encontro 11(síncrono) - Encerramento do módulo (presencial/síncrono) \\
\hline
\end{tabular}


O primeiro dos encontros serviria para a apresentação da dinâmica de trabalho do curso. Os encontros seguintes intercalariam entre apresentações das lições e encontros sobre dúvidas a respeito dessas lições. Os últimos encontros teriam como foco o levantamento de situações-problema reais, e a elaboração de ensaios de solução a essas. Essa dinâmica de trabalho visaria (i) criação de um ritmo para os participantes, envolvendo familiaridade e novidades durante o decorrer do curso de extensão, (ii) consideração e diálogo entre aquilo que é interno e externo ao curso de extensão, do oferecido pelos participantes e do trazido de fora do curso de extensão, e (iii) fomento de discussões sobre o valor de se dispor de Práticas Educacionais Abertas no Ensino de Física, enfocando a utilização e produção de Recursos Educacionais Abertos.

A dinâmica do curso foi planejada de modo que tivesse como fundamento o trabalho colaborativo dos participantes. Essa escolha teve como objetivo oportunizar o surgimento de um compromisso mútuo entre os participantes, que por sua vez é necessidade básica para a formação de uma comunidade de prática (WENGER, 2001, p. 101). Levando em consideração a criação de espaços públicos e privados para o surgimento das $\mathrm{CoP}$, além da logística de trabalho na modalidade a distância, foi estabelecido que os licenciandos participantes do curso fossem divididos em diferentes equipes de trabalhos. Essas seriam, idealmente, mantidas durante todos os trabalhos realizados no curso - ainda que não tenha sido possível. As equipes teriam de quatro a cinco participantes. Nos grupos, seriam realizados todos os ensaios de solução correspondentes às situações-problema do curso de extensão. O critério para a divisão das equipes seria a diversidade de instituições de ensino, permitindo um maior intercâmbio entre os participantes.

A Comunidade de Prática, que se pretendia cultivar a partir do curso de extensão, necessitaria de um ambiente virtual para que pudesse existir. As experiências da equipe de coordenação levaram à escolha do Rocket. Chat ${ }^{4}$ como instrumento para a comunicação dos participantes. Trata-se de uma plataforma de comunicação open source ${ }^{5}$, que permite aos usuários uma comunicabilidade segura na web, em dispositivos móveis e em computadores. O sistema permite, além de conversas diretas entre dois usuários, a criação de canais abertos e grupos privados para discussões e compartilhamento de arquivos entre muitos participantes. Nesse sentido, auxiliou não só como uma ferramenta de comunicação e de criação de compromisso mútuo entre os participantes, mas também como uma primeira proposta de convite a diferentes níveis de participação.

Investiu-se tempo no projeto de uma estrutura para o Rocket.Chat, capaz de abarcar o curso de extensão e a potencial CoP. Foram criados grupos privados para as diferentes equipes de trabalho, além das salas abertas:

\footnotetext{
${ }^{4}$ Para maiores informações, acesse <http://www.rocket.chat/>. Acesso em: abr. 2019.

${ }^{5}$ Em português, Código Aberto.
} 
- \# Avisos: sala em que professores e tutores poderiam publicar avisos para os demais participantes. Não permite respostas, facilitando uma visão rápida das informações relevantes para o andamento do curso de extensão.

- \# Cafeteria: espaço para "conversas na hora do café", para que os participantes pudessem trocar mensagens sobre assuntos que não necessariamente tivessem ligação com o tema de REA.

- \# Divulgação-de-Lições: nessa sala seriam divulgados os materiais relacionados às lições dos módulos. Os licenciandos não poderiam responder às mensagens divulgadas nesse canal, de modo que as lições pudessem facilmente ser encontradas por todos os participantes.

- \# Dúvidas-das-Lições: sala destinada a concentrar as dúvidas dos participantes. Também foi idealizada como espaço para encontros síncronos, caso fosse necessário utilizá-la.

- \# Dúvidas-Rocket-Chat: esse canal serviria às dúvidas dos participantes em relação à plataforma.

- \# Open-Source: sala criada para incentivar o compartilhamento de recursos livres, open source e, em especial, REA.

A Fig. 1 apresenta a interface inicial do sistema desenvolvido para o curso de extensão.

Além da plataforma de comunicação, para que os participantes pudessem trabalhar em conjunto foi necessário buscar uma plataforma de trabalho colaborativo e um repositório online livres. Pela facilidade do seu uso, foram escolhidos o OwnCloud e o OnlyOffice ${ }^{6}$ como ferramentas para as atividades de colaboração do curso de extensão, e da posterior comunidade que poderia surgir dele. O OwnCloud é um sistema de compartilhamento, criação e armazenamento de documentos em nuvem, de natureza open source, sem limitação de espaço por usuário e número de usuários inscritos. Por sua vez, o OnlyOffice é um software de edição colaborativa e simultânea de documentos, também de natureza open source. Para o curso, utilizamos o OnlyOffice enquanto extensão de nosso servidor do OwnCloud - chamado CrefCloud - de modo a possibilitar a criação, edição, armazenamento e compartilhamento dos trabalhos desenvolvidos pelos participantes.

\footnotetext{
6 Para maiores informações, acesse <https://owncloud.org/> e <https://www.onlyoffice.com/>.Acesso em: abr. 2019.
} 


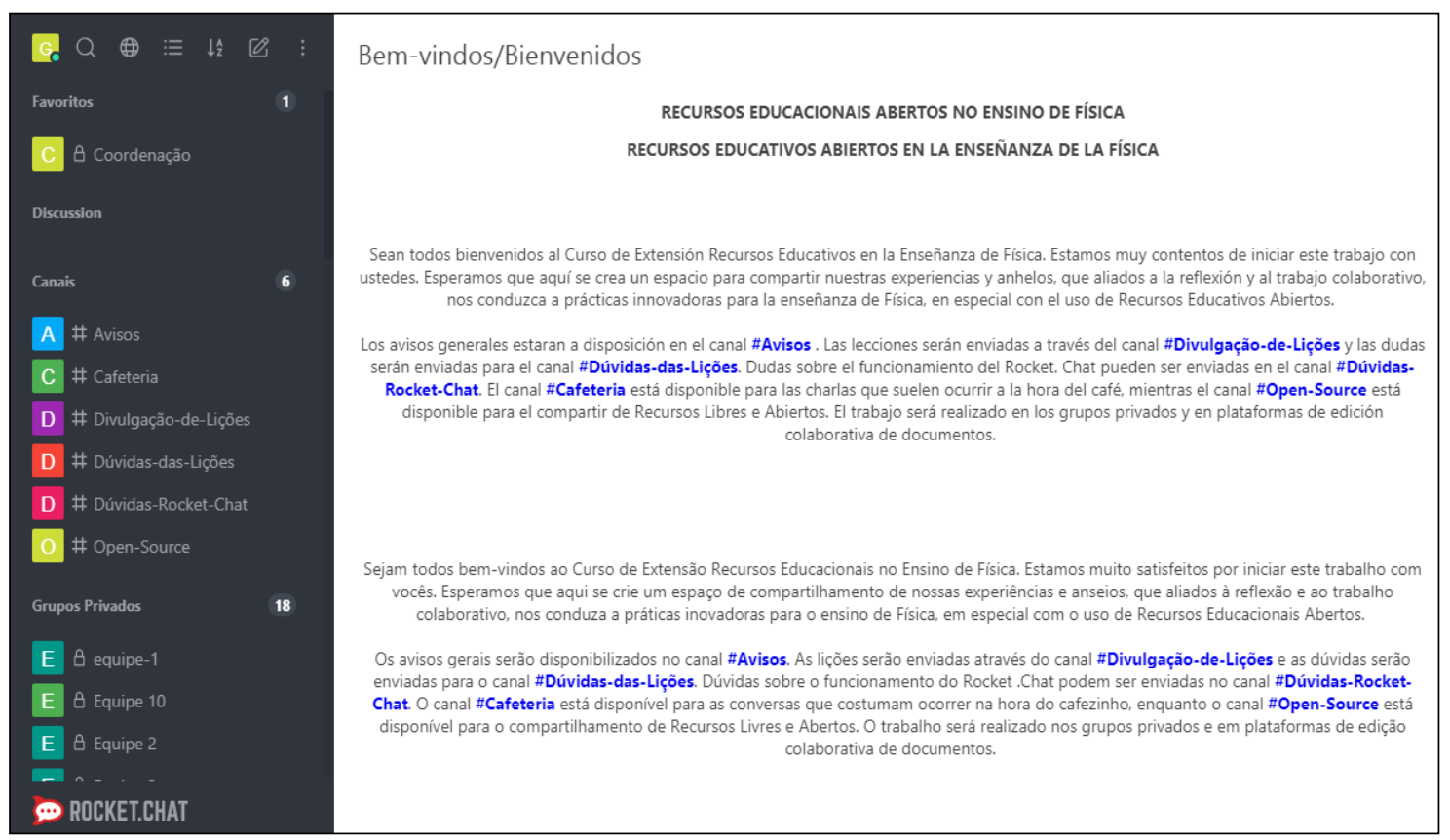

Fig. 1 - Interface inicial do ambiente virtual Rocket.Chat.

Para que se criasse uma logística do curso de extensão, foi necessário recorrer a outros aplicativos e softwares open source. O sistema MConf, um sistema open source de comunicação online em vídeo, foi escolhido para realizar as webconferências durante os encontros síncronos entre os participantes do curso. Uma alternativa, em caso de dificuldades técnicas relacionadas ao uso desse sistema, estaria na transmissão ao vivo no site YouTube, através do uso do software open source OBS Studio. Consideramos adequado o uso desse Open Broadcaster Software como recurso secundário, devido às transmissões serem realizadas em uma rede social não-livre, apesar de acesso gratuito. Também planejou-se utilizar o aplicativo $\mathrm{Du}$ dle para realização de todas as votações relacionadas a horários, sempre que necessário. Vale ressaltar a importância atribuída aos valores de conhecimento livre, fundamentais nessas escolhas. Em nossa visão, os valores importantes para a potencial comunidade de prática deveriam ser priorizados já na construção do curso de extensão e apresentados e destacados durante seu desenrolar.

As atividades avaliativas foram planejadas de modo que todos pudessem delas participar. Não apenas professores e tutores tiveram a oportunidade de avaliar as produções das diferentes equipes de trabalho, mas também foi possível aos licenciandos valorizar e avaliar os trabalhos produzidos por outros participantes. Além disso, a autoavaliação da sua participação teve peso na dinâmica avaliativa do curso. Um Protocolo de Avaliação comum foi elaborado, ainda que aberto a modificações, de maneira a orientar as avaliações.

Como já adiantado, o planejamento descrito passou por modificações advindas das necessidades e das dificuldades técnicas encontradas durante a concretização do curso. Ainda assim, essa parece ser uma das maiores vantagens do planejamento à luz da teoria da aprendi- 
zagem social de Wenger: é possível aproveitar o emergente, que no fundo é o que faz uma Comunidade de Prática (WENGER, 2001, p. 314). Na próxima sessão, relatamos a experiência do curso de extensão, ocorrida no primeiro semestre de 2018.

\section{A Experiência}

Durante os meses de abril a julho de 2018 foi realizado o curso de extensão internacional Recursos Educacionais Abertos para o Ensino de Física. O período de inscrições ocorreu de 20 de março a 11 de abril, através do envio de uma mensagem de e-mail dos interessados para a equipe coordenadora do curso. Àqueles que solicitaram inscrição no curso foi enviado um link para a votação do melhor horário para a realização dos encontros síncronos, realizado através do aplicativo de agendamento Dudle. A votação, aberta durante uma semana, permitiu que fossem escolhidas as sextas-feiras, das 13h-14h no horário de Bogotá (15h16h no horário de Brasília), como datas para a realização dos encontros síncronos. Os encontros síncronos, inicialmente, estavam previstos para acontecer nos polos EAD das Instituições de Ensino Superior participantes.

A inscrição solicitada foi confirmada a partir da disponibilidade para a participação em encontros síncronos. Ao final do período de inscrição havia 40 licenciandos de Física dispostos a se engajarem nas atividades do curso. Treze licenciandos de uma das instituições de Ensino Superior colombiana e doze a partir da outra instituição participaram do curso. No Brasil, dez alunos da UFRGS e cinco do IF-Sul/Visconde da Garça participaram.

No dia 27 de abril foi realizado o primeiro encontro do curso, contando com a participação de 30 dos 40 licenciandos inscritos, dos professores ministrantes do curso, dos tutores e dos professores colaboradores. Foi realizado de modo síncrono, com todos os participantes reunidos em uma das quatro instituições, através do sistema MConf. Todos tiveram a oportunidade de se conhecer e expor suas expectativas em relação ao curso. Durante o encontro, foi explicada a dinâmica que seria adotada durante o curso e a intenção de proporcionar um ambiente de aprendizagem colaborativa sobre Recursos Educacionais Abertos. Além disso, foram apresentadas aos participantes as ferramentas digitais que seriam utilizadas durante o curso - o Rocket.Chat, o CrefCloud e o OnlyOffice. Apesar das dificuldades associadas às diferenças linguísticas, e a problemas técnicos relacionados aos equipamentos utilizados para realizar a webconferência, todos os participantes se mostraram animados com as perspectivas abertas pelo curso.

Durante a semana que se seguiu, foram criados os usuários para cada um dos participantes. Já na plataforma Rocket.Chat, foi pedido para que cada um fizesse uma pequena apresentação no canal \#Cafeteria, falando um pouco de si, de seus gostos e interesses e de sua trajetória em relação ao Ensino de Física. Essas informações foram utilizadas para a divisão dos grupos de trabalho. Além disso, foi disponibilizado espaço na sala \#Dúvidas-Rocket-Chat, para a solução de eventuais dificuldades relacionadas à plataforma. 
O segundo encontro, também síncrono através do sistema $M C o n f$, foi dividido em dois momentos. Durante o primeiro, foram divididas as equipes de trabalho - ordenadas de Equipe 1 à Equipe 10, compostas por quatro membros cada. Os participantes, ao serem chamados, conversavam com os colegas de grupo. No segundo momento foi apresentada a primeira lição do curso - Recursos Digitais e Objetos de Aprendizagem: Busca e Uso Adequado. Essa tinha como objetivo conscientizar sobre a relevância do uso de TDIC, em especial de Objetos de Aprendizagem (OA), marcado pela reflexão e inserção em um planejamento pedagógico feito pelo professor. Todos assistiram ao vídeo produzido pelos professores e tutores, contendo um resumo da lição e explicando a situação-problema a ser resolvida.

A situação-problema dessa primeira lição consistiu em buscar uma alternativa para as necessidades de um professor (hipotético) de Física do segundo ano do Ensino Médio, cuja matéria a ser lecionada fosse Óptica. A situação-problema incentivava os licenciandos a fazerem uso de concepções alternativas de Física já encontradas na literatura de Ensino de Física. Entre elas, estão: a visibilidade dos raios de luz e seu alcance finito; a confusão entre propagação de raios paralelos e propagação retilínea; a emissão de apenas um raio de luz por ponto luminoso; a interpretação de diferentes naturezas para luz natural e luz artificial; e a compreensão da luz como um fluido estático (ALMEIDA; CRUZ; SOAVE, 2007).

Após o vídeo, licenciandos e professores debateram sobre os principais pontos da situação-problema, de modo que ela fosse compreendida. Ao mesmo tempo, foi disponibilizado no canal \#Divulgação-de-Lições o texto completo da lição, contendo informações sobre a busca de recursos digitais e alguns critérios a serem levados em conta na sua escolha. Os critérios apresentados foram: a validade do conteúdo do recurso; o seu ajuste às metas de ensino e de aprendizagem; seu design; a possibilidade de interatividade; e os modos de aplicação a que seria submetido. Durante uma semana, os alunos discutiram acerca de recursos que possivelmente seriam úteis para um ensaio de solução do problema. Foi disponibilizado aos licenciandos um protocolo com Critérios de Avaliação de Recursos Digitais, para que cada equipe pudesse avaliar os recursos encontrados.

No terceiro encontro, também síncrono através do MConf, alguns dos licenciandos trouxeram suas dúvidas para uma discussão sobre a situação-problema. Em especial, foi preciso frisar a necessidade de leitura do texto fornecido. Outras dúvidas pertinentes se referiam à possibilidade de enquadramento de um recurso digital como OA e acerca das concepções alternativas associadas ao ensino de Óptica. Após o momento de dúvidas, os professores e tutores esclareceram o sistema de avaliação: as produções das equipes não seriam avaliadas somente por seus integrantes, mas também por outras equipes. Foram divididas as produções, de modo que cada trabalho produzido fosse avaliado por integrantes de outro grupo. Também foi fornecido o Protocolo de Avaliação, para facilitar e tornar comparável as avaliações dos diversos participantes. Em comum acordo, foi combinado que a avaliação deveria ser realizada em até uma semana após sua conclusão. 
Esse encontro foi mais breve, devido a interferências técnicas no MConf. O sistema apresentou problemas relacionados à qualidade da transmissão dos encontros síncronos, exigindo uma mudança na dinâmica do curso de extensão. Na semana seguinte, optou-se por utilizar um meio de comunicação alternativo - com vídeos gravados ou transmissões ao vivo no site YouTube realizadas através do software open source OBS Studio. As diferentes equipes se empenharam muito em suas atividades, trabalhando em conjunto para a elaboração de seus ensaios de solução. Nos ensaios de solução elaborados no OnlyOffice foram discutidos principalmente simulações computacionais, prioritariamente do repositório online PhET Interactive Simulations ${ }^{7}$. Foram apontadas potencialidades e limitações desses recursos, com base nos critérios descritos na lição. Os trabalhos foram finalizados antes do próximo encontro síncrono.

Devido aos problemas técnicos enfrentados, o quarto encontro foi realizado na sala \#Dúvidas-das-Lições. Iniciou com algumas dúvidas acerca do modo de realização das avaliações e sobre a finalização dos trabalhos. Em seguida, foi apresentado aos licenciandos um vídeo, gravado por um dos professores e um dos tutores, apresentando a Lição 2 - Recursos Educacionais Abertos. Teve como objetivo apresentar o conceito de REA, seu desenvolvimento histórico e os diferentes tipos de licenciamento livre.

A segunda situação-problema proposta aos licenciandos, decorrente da tarefa anterior, consistiu na elaboração de um REA, na forma de um guia de atividades para um dos Objetos de Aprendizagem escolhidos pelo grupo. Enquanto todos assistiam o vídeo produzido para este encontro foi disponibilizado o texto integral da Lição 2 no canal \#Divulgação-deLições. No texto podiam ser encontradas informações sobre o movimento Open Source, seu desenvolvimento histórico, sobre os Recursos Educacionais Abertos, sobre o significado de suas qualidades enquanto livres e abertos e sobre as Licenças Abertas sob os quais serão licenciados.

Assim como na lição anterior, após uma semana de trabalhos e da realização das avaliações dos trabalhos anteriores, houve um encontro de dúvidas para os grupos que sentissem a necessidade. As dúvidas trazidas pelos estudantes se relacionavam muito com a liberdade e abertura característica dos REA. Um dos tutores apresentou aos alunos um vídeo em que detalhava o funcionamento das Licenças Abertas, explicando como elas auxiliam tanto na proteção dos direitos autorais daqueles que produzem conteúdos livres quanto na difusão e apropriação desses recursos. Após o encontro, os alunos tiveram mais uma semana para trabalhar em suas equipes.

Outras dificuldades foram encontradas nessas primeiras semanas de curso. A primeira delas foi a questão da língua em que se daria a comunicação dos grupos, a escrita dos trabalhos e as avaliações. Cada grupo elegeu sua forma de comunicação: alguns se centraram no português, outros no espanhol. O mais comum, porém, foi a escolha de que cada um se comu-

\footnotetext{
${ }^{7}$ Projeto da Universidade do Colorado, busca a difusão de simulações interativas livres, nos temas de ciência e matemática. Para mais informações, acesse <https://phet.colorado.edu/>. Acesso em abr. 2019.
} 
nicaria na língua em que tivesse mais facilidade, e buscaria os meios de compreender as mensagens dos colegas. Um segundo desafio foi a evasão de alguns dos licenciandos matriculados, ocorrendo casos de participação mínima até um total desligamento com o curso. Isso causou problemas nas equipes de trabalho, em alguns casos reduzidas a um ou dois participantes ativos. Para contornar esse problema, entrou-se em contato com todos aqueles que evadiram, buscando saber os motivos da não-participação; em especial, o desejo era de se certificar de que não se tratavam de problemas técnicos relacionados aos recursos utilizados, ou de qualquer outro problema que não pudesse ser resolvido. Após esse contato, constatou-se um grupo de 29 licenciandos ativos no curso. A partir desse número, os grupos foram redistribuídos, priorizando-se a junção de equipes de trabalho com menos indivíduos ativos. Não houve mais evasões a partir desse momento.

O sexto encontro síncrono foi iniciado com uma discussão sobre a Lição 3. Seu tema foi Estratégias de Uso de REA e Práticas Educacionais Abertas (PEA), levando o conceito de REA à prática educacional através do conceito de PEA, servindo também à discussão da avaliação no processo de ensino e de aprendizagem em contextos educacionais. Nesse encontro os professores, tutores e licenciandos optaram por modificar a dinâmica de trabalho que vinha sendo adotada. As situações-problema idealizadas foram abandonadas e proposto que as equipes buscassem problemas reais de sala de aula que pudessem ter no uso de REA e na elaboração de PEA um ensaio de solução.

Assim, a terceira situação-problema seria proveniente das vivências dos membros das equipes, que as apresentariam ao grande grupo no encontro referente à próxima lição. Orientou-se que cada membro apresentasse uma situação-problema aos seus colegas e que, como equipe, fosse escolhida uma que a representaria.

Em um segundo momento, os tutores realizaram uma avaliação geral do andamento do curso. Foram destacados os pontos positivos, como a adaptação aos recursos de trabalho colaborativo livre e as discussões de teor didáticos acerca dos recursos, e alguns pontos a melhorar, como a questão da pro-atividade individual. Em seguida, foram apresentadas as novas distribuições das equipes de trabalho, ordenadas de Equipe A à Equipe G. Os licenciandos ainda tiveram tempo de apresentar algumas dúvidas sobre quais tipos de situação-problema poderiam ser trazidas. Durante uma semana, puderam trabalhar com suas equipes nesse reconhecimento dos desafios enfrentados pelos professores de Física em seus diversos contextos sociais e culturais.

O sétimo encontro do curso de extensão serviu para que os alunos trouxessem qualquer dificuldade que estivessem enfrentando para a identificação de situações-problema da prática docente. Realizada no canal \#Dúvidas-das-Lições, foi iniciado com a apresentação de um vídeo sobre o Método Predizer, Observar, Explicar (P.O.E.), de modo a motivar os alunos a pensar em situações-problema capazes de ser resolvidas com inovações nas práticas didáticas. Surgiram dúvidas, sendo as mais comuns sobre o conteúdo e a abrangência dos problemas a serem identificados. Solicitou-se que as equipes enviassem suas situações-problema até 
o dia anterior ao próximo encontro síncrono, de modo que tutores e professores pudessem organizá-las e sistematizá-las. Ao final do encontro, combinou-se que seria realizada uma votação das duas situações-problema a serem trabalhadas pelos participantes do curso.

O oitavo encontro foi realizado através de uma transmissão ao vivo no site YouTube, utilizando o software open source OBS Studio. Um dos professores e um dos tutores apresentaram, na transmissão ao vivo, uma síntese das propostas levantadas pelas diferentes equipes de trabalho. Foram trazidas situações-problema como: a falta de interesse dos estudantes, que consideram os conhecimentos de Física como irrelevantes em suas vidas; a falta de contextualização dos conhecimentos de Física; o uso do hardware livre Arduino para a problematização da relação entre modelos científicos e atividades experimentais; a possibilidade do Ensino de Física em classes hospitalares; e como trazer uma TDIC para um planejamento de atividade didática. Ao final do encontro, foi proposto que os licenciandos votassem em situaçõesproblemas de equipes diferentes da sua e sugerissem melhorias, como a expansão do seu domínio de conteúdo ou a especificação de situações-problema vagas. Para isso, foi enviado aos participantes um formulário.

Algumas das atividades foram comprometidas durante a semana que se seguiu, devido a problemas no servidor em que estava lotado o CrefCloud. Isso impossibilitou que os licenciandos pudessem comentar e sugerir melhorias às situações-problema. $\mathrm{O}$ problema no servidor foi resolvido durante o horário do encontro síncrono da nona semana de curso. Nesse encontro, foram divulgadas as duas situações-problema mais votadas pelos participantes do curso:

a primeira, relacionada com a falta de interesse demonstrada pelos estudantes em relação aos conhecimentos de Física;

a segunda, relacionada aos meios de incorporação das TDIC no planejamento de aula.

O tempo foi utilizado pelas equipes para a escolha entre uma das situações-problema e para dar início à organização para a realização dos trabalhos. Em consonância com isso, a equipe de coordenação decidiu que o encontro síncrono da semana seguinte a essa, que seria o último encontro do curso de extensão, fosse dedicado para que os licenciandos pudessem conversar e desenvolver um ensaio de solução. Isso foi necessário para contornar a escassez de tempo dos estudantes, que enfrentavam o final de semestre letivo de seus cursos de graduação.

Essa decisão levantou a necessidade de um encontro síncrono extra, originalmente marcado para o dia 06 de julho de 2018. Foi necessário, porém, postergar durante mais uma semana em função de um jogo da Seleção Brasileira na Copa do Mundo de 2018. Assim, o décimo-primeiro encontro aconteceu no dia 13 de julho de 2018. Foi realizado de modo síncrono, através de uma transmissão ao vivo utilizando o software OBS Studio. Durante o encontro, foi realizada uma apreciação dos trabalhos produzidos pelos diversos grupos, através de uma retrospectiva das vivências e histórias de aprendizagem ocorridas ao longo do curso. 
O fechamento do curso, em clima de um breve adeus, foi marcado pelo incentivo da continuidade do trabalho realizado.

\section{Comentários finais}

O curso de extensão Recursos Educacionais Abertos para o Ensino de Física, realizado entre abril e julho de 2018, contou com a participação inicial de 47 membros, sendo 40 licenciandos em Física e uma equipe de coordenação de dois professores ministrantes, três professores colaboradores e dois tutores. Ao longo de onze encontros, os licenciandos trabalharam no ensaio de solução de situações-problema ideais, similares às vividas por professores de Física no cotidiano da sala de aula, além da busca de situações-problema reais de sala de aula.

Ainda que os encontros síncronos fossem previstos inicialmente para ocorrer no polo de EAD da UFRGS, houve problemas técnicos que exigiram alterações no planejamento inicial. Sua efetivação em encontros síncronos na modalidade de conferência web não se sustentou, passando a ser realizado em salas da plataforma Rocket.Chat ou através de transmissões ao vivo no site YouTube. As equipes de trabalho iniciais também precisaram ser repensadas, devido à evasão de 11 licenciandos- todos por falta de tempo para dedicar-se ao curso de extensão. Esse número corresponde a $27,5 \%$ do total de inscritos, sendo comparável à faixa de evasão correspondente a maior quantidade de cursos a distância não-formais em instituições públicas de educação - de 26\% a 50\% - segundo dados informados no censo 2017 da Associação Brasileira de Educação a Distância (ABED, 2018, p. 183).

Após o final do curso de extensão, alguns dos licenciandos demonstraram animação em atender o convite de continuidade das atividades realizadas. Das conversas entre esses participantes, nos espaços públicos e privados, surgiu o interesse na divulgação das vivências do curso de extensão. Quatro licenciandos, um dos tutores e um professor colaborador, elaboraram um trabalho intitulado "Curso virtual sobre Recursos Educativos Abiertos para la Enseñanza de la Física: una experiencia colaborativa entre licenciados en Física" para apresentação na XXI Semana de Enseñanza de la Física, realizada na Universidad Distrital Francisco José de Caldas em setembro de 2018. No trabalho, relataram as experiências de aprendizagem colaborativa vivenciadas no curso, destacando a importância do trabalho realizado para a conscientização sobre a utilização de Recursos Educacionais Abertos no Ensino de Física. Além disso, comentaram os principais aspectos do curso: o investimento em situaçõesproblema, a estrutura e trabalho realizado em grande parte com recursos livres e a interação e colaboração com licenciandos em Física de outro país.

O desenvolvimento dessa apresentação consolidou o desejo de continuar um compromisso mútuo. Foi criada uma sala no Rocket.Chat, chamada \#Proyecto-REA, onde esses membros pudessem interagir. Também foi aberta a possibilidade de que novos professores se agregassem, o que efetivamente ocorreu. Nesse momento, professores de física (em exercício e em formação inicial) continuam colaborando na elaboração de um e-book, com tema de ele- 
tromagnetismo, licenciado como Recurso Educacional Aberto. Alguns dos participantes desse empreendimento conjunto apresentaram a comunicação intitulada "Comunidad Virtual de Práctica de profesores de Física: una experiencia colaborativa en la elaboración de un Recurso Educativo Abierto (REA) para la enseñanza de la Electrostática en educación media", no I Seminario Internacional de Innovación em Educación y Didáctica de las Ciencias ${ }^{8}$, realizado em julho de 2019 na Universidade de Antioquia, Medellin.

Portanto, nossa avaliação inicial é de que o curso, de caráter formal, alcançou o objetivo para o qual foi planejado. Tornou-se, aos poucos, um espaço para a aprendizagem colaborativa sobre REA e possibilitou um compromisso entre participantes. Sendo planejado com base nos sete princípios de cultivo de Comunidades de Prática propostos por Wenger, McDermott e Snyder (2002), serviu de base para o surgimento de uma potencial comunidade de prática de licenciandos e pesquisadores, interessados no uso, desenvolvimento e compartilhamento de REA no Ensino de Física, de caráter não-formal. Reservamos, ainda, o cuidado de denominá-la potencial, pois reconhecemos a necessidade de uma avaliação rigorosa a partir dos critérios determinados pela teoria de Wenger. Essa análise, em andamento, está além dos objetivos desse artigo.

\section{Agradecimentos}

Os autores agradecem à Profa. Sonia López Ríos, da Universidade de Antioquia, Medellin, e ao Prof. Fabio Omar Arcos Martínez, da Universidade Distrital Francisco José de Caldas, Bogotá, pelo apoio dado aos participantes de suas instituições. Os dois primeiros autores agradecem a bolsa proporcionada pela CAPES e o terceiro autor agradece a bolsa produtividade do CNPq.

\section{Referências}

ABED. ASSOCIAÇÃO BRASILEIRA DE EDUCAÇÃO A DISTÂNCA. Censo EAD.BR: relatório analítico da aprendizagem a distância no Brasil. Curitiba: InterSaberes, 2018.

AKERSON, V. L.; DONNELY, L. A.; RIGGS, M. L.; EASTWOOD, J. L. Developing a Community of Practice to Support Preservice Elementary Teachers' Nature of Science Instruction. International Journal of Science Education, v. 34, n. 9, p. 1371-1392, 2012.

ALMEIDA, V. de O.; CRUZ, C. A. de; SOAVE, P. A. Concepções alternativas em óptica. Porto Alegre: Instituto de Física, Programa de Pós-Graduação em Ensino de Física, 2007. v. 18.

ANDRADE, R. S. de; COELHO, G. R. Tecnologias Digitais da Informação e Comunicação em cursos de licenciatura em Física de uma universidade pública federal: "usos" estabelecidos

\footnotetext{
${ }^{8}$ Para mais informações, visitar a página do evento em <http://mcie.itm.edu.co/sied2019>.
} 
por professores universitários no processo de formação inicial. Caderno Brasileiro de Ensino de Física, v. 35, n. 3, p. 888-916, 2018.

ARIMOTO, M. M.; BARROCA, L.; BARBOSA, E. F. Recursos Educacionais Abertos: aspectos de desenvolvimento no cenário brasileiro. Revista de Novas Tecnologias no Ensino, v. 12, n. 2, 2014.

CLARKE, L. The POD model: Using communities of practice theory to conceptualise student teachers' professional learning online. Computers \& Education, v. 52, p. 521-529, 2009.

DANTAS, C. S.; GERMANO, M. G.; MOITA, F. M. G. da S. C.; LUNA, E. M. Ensinar e Aprender Física com Apoio de Recursos Digitais: Enfoque na Aprendizagem Significativa. Informática na Educação: teoria \& prática, v. 17, n. 1, 2014.

EL-HANI, C. N.; GRECA, I. M. ComPratica: A Virtual Community of Practice for Promoting Biology Teachers' Professional Development in Brazil. Research in Science Education, v. 43, n. 4, p. 1327-1359, 2013.

GARCÍA, J. M.; GRECA, I. M.; MENESES, J. Á. Comunidades virtuales de práctica para el desarrollo profesional docente en Enseñanza de las Ciencias. Revista Electrónica de Enseñanza de las Ciencias, v. 7, n. 2, p. 439-462, 2008.

GOHN, M. G. Educação não formal nas Instituições Sociais. Revista do Programa de Pósgraduação em Educação da Unochapecó, v. 18, n. 39, p. 59-75, 2016.

GRETTON, A. L.; BRIDGES, T.; FRASER, J. M. Transforming physics educator identities: TAs help TAs become teaching professionals. American Journal of Physics, v. 85, n. 5, p. 381-391, 2017.

LOPES, R. P.; FÜRKOTTER, M. Formação inicial de professores em tempos de TDIC: uma questão em aberto. Educação em Revista, v.32, n. 4, p. 269-296, 2016.

MARTINEZ, R.; LEITE, C.; MONTEIRO, A. Os desafios das TIC para a formação inicial de professores: uma análise da agenda internacional e suas influências nas políticas portuguesas. Crítica Educativa, v. 1, n. 1, p. p. 21-40, 2015.

MARCOLLA, V. Como professores e alunos percebem as tecnologias de informação e comunicação nos cursos de licenciatura. In: REUNIÃO ANUAL DA ASSOCIAÇÃO NACIONAL DE PÓS-GRADUAÇÃO E PESQUISA EM EDUCAÇÃO, Anais... Caxambu: ANPEd, p. 1-13, 2008.

MEDEIROS, A.; MEDEIROS, C. F. Possibilidades e Limitações das Simulações Computacionais no Ensino de Física. Revista Brasileira de Ensino de Física, v. 24, n. 2, 2002. 
OEI. Organização dos Estados Ibero-americanos para a Educação, a Ciência e a Cultura. Metas Educativas 2021: A educação que queremos para a geração dos bicentenários. 2010. Disponível em: <https://www.oei.es/uploads/files/microsites/28/135/documento-completo.pdf >. Acesso em: abr. 2019.

SANTOS, A. I. dos. Educação aberta: histórico, práticas e o contexto dos recursos educacionais abertos. In: SANTANA, B.; ROSSINI, C.; PRETTO, N. de L. (Orgs.) Recursos Educacionais Abertos: práticas colaborativas e políticas públicas. São Paulo: Casa da Cultura Digital, 2012.

SANTOS, A. I. dos. Recursos Educacionais Abertos no Brasil: o Estado da Arte, Desafios e Perspectivas para o Desenvolvimento e Inovação. Tradução: DB Comunicação. São Paulo: Comitê Gestor da Internet no Brasil, 2013.

SCHUHMACHER, V. R. N.; ALVES FILHO, J. de P.; SCHUHMACHER, E. As barreiras da prática docente no uso das tecnologias de informação e comunicação. Ciência \& Educação, v. 23, n. 3, p. 563-576, 2017.

UNESCO. Declaração REA de Paris em 2012. 2012. Disponível em: <https://educacaoaberta.org/declaracao-mundial-sobre-rea/>. Acesso em: abr. 2019.

UNESCO. Diretrizes para Recursos educacionais abertos (REA) no Ensino Superior. 2015. Disponível em: <unesdoc.unesco.org/images/0023/002328/232852por.pdf>. Acesso em: abr. 2019.

UNESCO. Educação 2030: Declaração de Incheon e Marco de Ação para a implementação do Objetivo de Desenvolvimento Sustentável 4. 2016. Disponível em: <https://unesdoc.unesco.org/ark:/48223/pf0000243278_por>. Acesso em: abr. 2019.

WENGER, E. Comunidades de Práctica: aprendizaje, significado e identidad. Tradução:Genís Sánchez Barberán. Barcelona: Paidós, 2001.

WENGER, E.; McDERMOTT, R.; SNYDER, W. M. Cultivating Communities of Practice: a guide to managing knowledge. Boston, Massachusetts: Harvard Business School Press, 2002 .

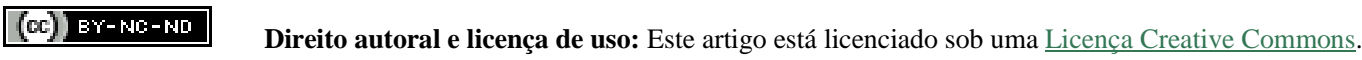

